\title{
THE QUALIFIED SELF, SOCIAL MEDIA AND THE ACCOUNTING OF EVERYDAY LIFE By Lee Humphreys
}

\author{
Reviewed by Erin Kincaid
}

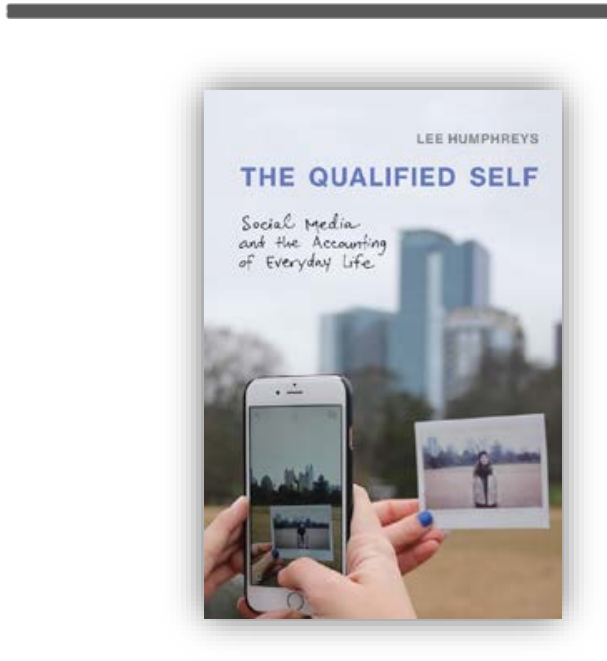

Cambridge, MA: MIT Press

2018

In her book, The Qualified Self: Social Media and the Accounting of Everyday Life, author, Lee Humphreys, makes a case from her ethnographic research that social media is an extension of autobiographical documentation that has been a part of human existence for hundreds of years (2018: 117). In offering this argument, she provides a rebuttal to the common opinion of social media use as a tool for the narcissist to feed their inner "centered-on-self factor" (44). In opposition to this widely-held public opinion, she states that social media is instead a tool of self-reflection, a reconciling of the ordinary, and part of the whole self emerging through the sharing of data $(5,9-11)$. With a variety of examples, Humphrey's demonstrates the ways in which individuals add to the collective voice and influence of society by the capture and dissemination of their "mundane events and activities" (26). She purports that these activities, though mundane and ordinary to some, are meaningful and important to others $(5,26)$. Therefore, due to these suppositions: the mundane as special, autobiography over narcissism, and the value of the personal collection and use of data,
\end{abstract}

Humphreys is able to explore and consider what social media really is in this era.

Humphrey's utilizes an expanded definition of the quantified self theory to further explain differences between personal data mining and data analysis (think Fitbit and diet tracking apps) (20-21). The quantified self theory states that an individual makes decisions and forms analyses after self-tracking, self-surveillance and self-discovery through mined data (21). The qualified self still observes oneself through media but monitors the shift of knowledge and use of the data differently (23). It is in those differences that Humphrey's research and argument lie, as well as questions and thoughts that arise while reflecting upon her text and theory.

This book is well written and easy to digest, a refreshing turn from the realm of laborious academic reads that sometimes constitute ethnography. Humphrey's examples of authentic social media dialogue and visuals create realism and provide an understanding of the public's views of ordinary social media interaction. In addition, Humphreys assists us to understand the rituals and uses of personal data memorialization. She provides historical content on the subject of autobiographical work, and practical scenarios which most social media users, and its naysayers, will recognize, along with alternative opinions on modern social media behavior.

In these examples, Humphreys uses theory to describe older media practices in contrast and comparison to present day media message trends (1921). For example, she states that for several centuries people have used media to create a memory of their daily activities, a process of reembracing the daily life for one's self $(4,28,32)$. They have shared their lives with loved ones and visitors on a variety of personal media tools, including diaries, photo albums, funeral pictures, vacation slideshows, baby books and so forth. These tools were the forerunners of Twitter, Facebook, Instagram and other digital platforms which are now the 'new norm' used for the posting of text and images that create this "remembrancing" process (74-75). These "technologies of the self" are a reckoning of sorts for 
individuals on a variety of levels (i.e. religious, historical data, communication, etc.) (92). Humphreys believes that diaries, which documented the lives of individuals now long gone, are not a far cry from the way in which the present-day person writes out the details of their life in one hundred and forty-four characters or less (4). She emphatically states that the social media feeding frenzy is not a den of penurious self-serving narcissist, but rather a communication tool that people use to account, record and reflect upon their lives.

I believe that an interdisciplinary approach to this research would be helpful. While I appreciate Humphrey's wide view of media and her use of journalistic concepts emerging from her background in communication (115-116), what is lost in her argument could be found in a partnership with psychology. Her research is based on the study of behavior, and with a subject as internalized and emotionally/psychologically motivated as communication, an investigation into internal experiences and motivations is needed. Also, her belief in humanity is optimistic, too optimistic in my view, even though I am an engaged social media handler. In my experience, there is also a darker side to the expressions of self found on social media.

While Humphreys compares the use of social media to the pocket diary, claiming that this modern tool is like the one used in the nineteenth century to catalog and capture one's day falls short. The significant difference lies in the expectation one has after the message is published. The pocket diary went back into one's pocket and was retrieved and shared with only those one was close to or was used as a tool to expedite the process of catching up over lost time. The use of social media is more public and heightens one's need for an immediate response from others to provide emotional gratification. One of the key themes the author uses when explaining the tools of both present and past is the concept of being "published." In my view, this term is appropriate only when speaking of modern mass media communication. The women who kept a daily log of visitors, ailments, weather patterns, religious reflections and resource consumption did not see their pocket diaries as a work being published. With publishing comes a different expectation of the work being written. One cannot compare the behaviors of the past with the present with the tools for autobiographies when different goals were and are to be achieved.

As a theological anthropologist, I would be remiss not to reflect upon Humphreys' work from my Christian perspective and understanding of faith. I view humanity as designed by God, who is continually composing the story of us, a story that is to be communicated to the world. Humphreys is wise to recognize this design in us and to see that no matter who the audience is, or how mundane the information may seem, each author is replicating that design by telling their story. I believe that we are designed to tell a story for the joy of telling our story, not for personal valuation.

Yet, with so many today trying to elicit a response from an audience and being concerned about the approval of that audience as opposed to the audience of One, abhorrent self-centered and narcissistic behaviors within the world of social media do emerge. This situation is tragic at two ends of a spectrum. On one end, we have the 'Julie' from 'Julie and Julia', who after cooking for the World Wide Web for almost a year, never realized she had not a single follower on her blog (Mark et al. 2009). Julie posted day after day, for months on end, because she was creating something special for herself. Her posts were an intrinsic affirmation of the activity she embarked upon daily. On the other hand, we have the Kardashians of the web. These represent the other, opposite, side of the spectrum, one where they tally income and revenue by post likes and shares. These are those who strive to be "influencers" through their autobiographical posts. The two parties represent very different uses of digital media, for the self or for public influence, but The Qualified Self seems to present only one, the selfreflecting digital autobiographer.

The book also fails to distinguish between the different audiences that are present on social media and their diverse purposes. The author states she is reflecting on the behaviors of the middle-aged personal cataloging individual. Yet by including the broad social media platforms in her data, she limits the accuracy of her research as each of those platforms represent significantly different sectors of society (26). Twitter is dominated by media influencers and appeals to a generation that speaks much differently than the typical middle-aged poster found on Facebook. (Salma 2019). Also, there seems to be a motive behind present-day declarations (tweets) that does not exist in the statements found in personal diaries from over one hundred years ago. To account for this, Humphrey's proposes a concept she refers to as a blurring of lines between the genre uses of media (31). Yet, I believe this is an 'apples and oranges' analogy, and that the only blurring of lines is found in the lack of honesty in present-day posts published throughout the web. It is no secret that often posts are scripted, actions and visuals that are created, prompted, and posed to provide a faux image or narrative. Young people especially seem to feel the need for affirmation from "likes" that equal statements of personal value.

Here is where the conversation should include input from both psychology and theology. Psychologically speaking, modern social technology encourages people to find personal value through a like, a share, or a comment-or the Holy Grail-all three. The nature of the pocket diary, prayer journal or daily 
memoir allowed for personal reflection to be the source of personal value and the reason to keep capturing one's thoughts and daily activities.

This difference is embedded in the changing social contexts between these different eras. Once we thought and acted for the betterment of the family unit and the community as a whole. We lived and acted for the protection of the communal. Now, what Humphreys would like to discard as not being a "me-centered" landscape is very much exactly that in the larger culture, and social media patterns and behaviors exemplify it. The mere fact that social media and similar technology is making its way into the American Psychological Diagnostic Manual, DSM (Pies 2009) is enough to rethink our author's dismissive notion that social media is the sweet action of a modern autobiographer who simply wants to connect with others and share the events of their day. There are those whose goal is this, yet they are not the only ones in the social media landscape, nor do they dominate the social media population.

I appreciated Humphrey's qualitative research in bringing new information to the table instead of rehashing out the repetitive common arguments regarding social media usage. This book opens up conversation to the incorporation of other viewpoints and allows for the expansion of research to include other disciplines, concepts and investigations. The sense of self that she believes is revealed through social media is not the distinctive statistics-centric "quantified self," but the more holistic, qualified self. Humphrey's argues that we come to understand ourselves in a new way through the representations of ourselves in personal autobiographical practices, both in these generations and from generations past (116, 117). Social media usage, data collection, dissemination through the messages we send to others for the completion of self are hardwired in more areas of the human experience than simple behavior and consumption. They are psychologically driven, humanistic in nature, represent emotional connection and are a collective representation of our spiritually designed needs, as well. Humphrey's text is an invitation to think about how our past connects to our activities today and how our patterns of communication may have larger implications and representations for our lives both individually and as a global society.

\section{References}

Humphreys, Lee. 2018. The Qualified Self, Social Media and the Accounting of Everyday Life. Cambridge, MA: MIT Press.

Mark, Laurence, Nora Ephron, Amy Robinson, Eric Steel, Scott Rudin, Donald J. Lee, Dana Stevens, et al. 2009.
Julie \& Julia. Culver City, Calif: Sony Pictures Home Entertainment.

Pies, Ronald. 2009. Should DSM-V Designate "Internet Addiction" a Mental Disorder? Psychiatry 6(2): 31-37.

Salma, Aslam. 2019. Twitter by the Numbers: Stats, Demographics \& Fun Facts. Omnicore Agency. URL: https://www.omnicoreagency.com/twitter-statistics/

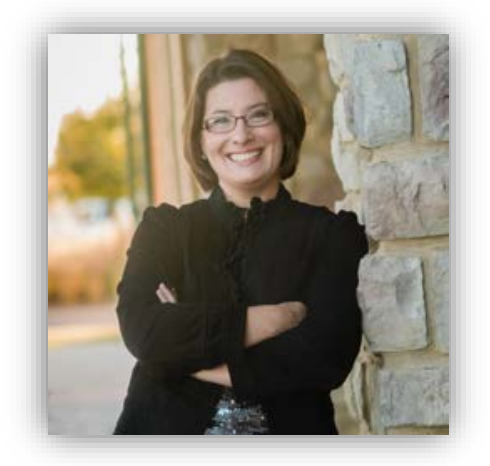

Erin Kincaid is a graduate student at Eastern University and in the thesis phase of the Master of Arts in Theological and Cultural Anthropology program. Her ethnographic research is focused on the cultural and religious sustainability practices of the Ghanaian community of North Texas. Erin works as the Senior Director of Education of Brighter Tomorrows, a domestic violence agency and women's shelter and serves as a faith-based counselor with Higher Hopes Counseling near Dallas, Texas. Erin's academic interests include studies in dignity, violence, human development-based counseling, generational and inter-communication behaviors.

Author email: erin.kincaid@eastern.edu 